\title{
Research on Fracture Initiation Pressure in Deviated Well of WCH9 Block
}

\author{
Siyu Xie ${ }^{1}$, Yongquan $\mathrm{Hu}^{2,}$, , Xiaojin Wan ${ }^{1}$, Shaowei $\mathrm{Wu}^{1}$, Liming $\mathrm{Cheng}^{1}$, Hui Yuan ${ }^{1}$ \\ ${ }^{1}$ Zhanjiang Branch of CNOOC, Zhanjiang, China \\ ${ }^{2}$ State Key Laboratory of Oil and Gas Reservoir Geology and Exploitation, Southwest Petroleum University, Chengdu, China
}

\section{Email address:}

xiesy@cnooc.com.cn (Siyu Xie), stimswpi@163.com (Yongquan Hu), wanxj2@cnooc.com.cn (Xiaojin Wan), yuanhui@cnooc.com.cn (Hui Yuan)

${ }^{*}$ Corresponding author

\section{To cite this article:}

Siyu Xie, Yongquan Hu, Xiaojin Wan, Shaowei Wu, Liming Cheng, Hui Yuan. Research on Fracture Initiation Pressure in Deviated Well of WCH9 Block. American Journal of Energy Engineering. Vol. 9, No. 2, 2021, pp. 41-47. doi: 10.11648/j.ajee.20210902.13

Received: April 22, 2021; Accepted: May 19, 2021; Published: May 24, 2021

\begin{abstract}
Highly-deviated well are applied for effectively developing WCH9 gas field with deep buried and low permeability, and the payzone are candidates for hydraulic fracturing by evaluation of gas reservoir. Therefore, fracture initiation pressure is a key parameter for design of hydraulic fracturing treatment. Firstly, a series of experiments were completed by core sample from target formation, Young's modulus is about $13 \mathrm{GPa}$ and Poisson's ratio is 0.286 at a confining pressure of $40 \mathrm{MPa}$, horizontal principal stress is $78 \mathrm{MPa}$ and $63 \mathrm{MPa}$, and in-situ stress profiles were interpreted by logging data. Then, the formation rock is regarded as isotropic linear elastic material, thus total stresses distribution on the deviated wellbore wall was determined by stress superposition principle, in which in-situ stress redistribution around the deviated wellbore, fluid pressure acted on the borehole wall and filtration stress are taken into account when fracturing fluid was injected into wellbore. Further, prediction model of fracture initiation pressure was established by applying criterion of maximum tensile stress and effective stress transformation. Lastly, according to the borehole trajectory, in-situ stress and other parameters from payzone of WCH9 block, fracturing initiation pressure varied with Deviation angle and azimuth angle were computed by numerical simulation method, these results provide a basis for optimization design of hydraulic fracturing technology parameters.
\end{abstract}

Keywords: Deviated Well, In-situ Stress, Fracture Initiation Pressure, Hydraulic Fracturing

\section{Introduction}

Hydraulic fracturing is a widely used stimulation technique in petroleum and gas industry for enhanced hydrocarbon production and recovery from low-permeability oil/gas reservoirs. Fracture initiation pressure (FIP) was required in order to perform an efficient hydraulic fracture stimulation treatment. Location of initial fractures and the breakdown pressure of these hydraulically fractures in inclined wellbores are important in many other operations such as sand-control and production optimization. A lot of research has proven that FIP and path is closely related to in-situ stresses and well bore hole trajectory.

Hubbert first considered that the hydraulic fracture will be created by increasing wellbore fluid pressure when tensile tangential stresses exceed tensile strength of the formation [1].
Yew pointed out that rock tensile strength and formation fluid pressure have an important influence on rock breakdown pressure, and simplified the FIP prediction model according to the first strength theory [2]. Wan summarized the previous formulas on FIP prediction for vertical open-hole wells [3]. Daneshy raised the issue for the first time by performing theoretical and experimental investigation on inclined hydraulic fractures [4].

$\mathrm{Yu}$ and Zhou presented the model of stress distribution on the wall of arbitrary inclined well, calculation method on FIP and breakdown location in base of maximum tensile strength criteria $[5,6]$. Considering formation fluid pressure, operating conditions, fracturing fluid leak effect, and so on, Chen proposed the calculation method of FIP of deviated well [7]. Hossain discussed the influence of wellbore trajectory, perforation and stress range under arbitrary deviation or azimuth angle on initiation and extension during hydraulic 
fracture job [8].

Weng displayed the results of an analytical study of fracture initiation and propagation from inclined wellbores. He presented a criterion that correlates fracture link-up to wellbore parameters and investigated the impact of the horizontal stress anisotropy and multiple fracture formation [9]. Shi believes that the porous elastic inclined well model is more appropriate for arbitrary deviated wells by calculating and analyzing the influences of relating parameters on $\operatorname{FIP}_{[10]}$ Zeng established a simulation model of FIP of open-hole well by applying the maximum tensile stress theory according to effective stress, and analyzed the influence of infiltration effect on FIP of open holes [11].

Zhu believes reservoir damage has an important influence on the FIP in hydraulic fracturing, a new prediction model of FIP was established for a random inclined well by considering an additional fracturing fluid infiltration pressure according to the empirical relationship of permeability and porosity combined with Darcy's law of fracturing fluid in poro-elastic media [12].

Roostaei proposed a new analytical model for hydraulic fracture initiation in deviated wellbores, the results displayed that the in-situ stresses state depended on the reverse, strike-slip or normal faulting regime, has a significant impact on the effect of azimuth and inclination on the FIP [13].

The target formation of WCH9 gas field has a buried depth of $3800-4000 \mathrm{~m}$, reservoir temperature is approximately $160^{\circ} \mathrm{C}$, and effective permeability is about $0.02-0.46 \mathrm{mD}$. In order to effectively enhance hydrocarbon production in the block, highly-deviated well are used and the payzone are candidates for hydraulic fracturing. Obviously, fracture initiation pressure is an important parameter for reasonable scheme design of hydraulic fracturing treatment.

In this study, a series of experiments, such as rock modulus (YM) and Poisson's ratio (PR) as well as in-situ stress, were completed. Then, the prediction model of FIP in arbitrarily oriented wellbore was established according to effective stress principle and maximum tensile stress criterion. So, FIP and its variation law was obtained according to parameters from the payzone of WCH9 block.

\section{Experimental Study on Rock Mechanics Parameters}

Rock core sample drilled from target formation of WCH9 block, and experiment instrument is RTR-1000 high temperature and high pressure tri-axial mechanics testing system (MTS).

According to recommended standard practice, Young's elastic modulus and Poisson's ratio of core sample are calculated by stress-strain curve of rock sample. The experiment curves were shown in Figure 1. YM and PR experimental results of the samples were shown in Table 1.

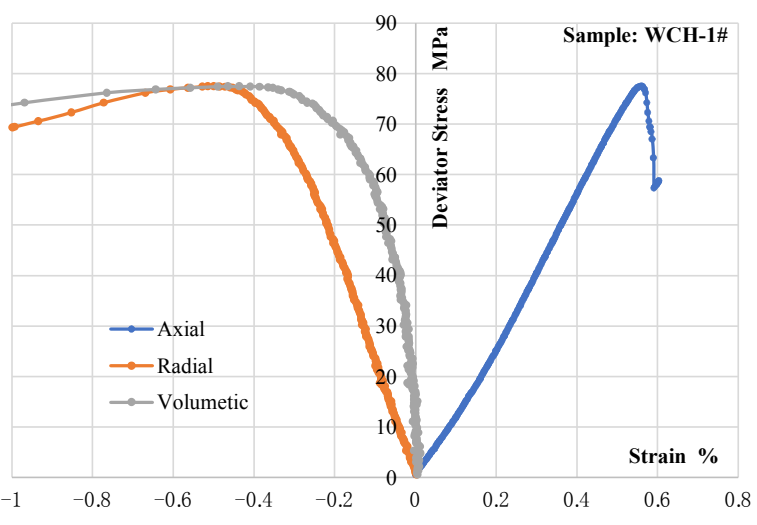

(a) Sample: WCH-1\#

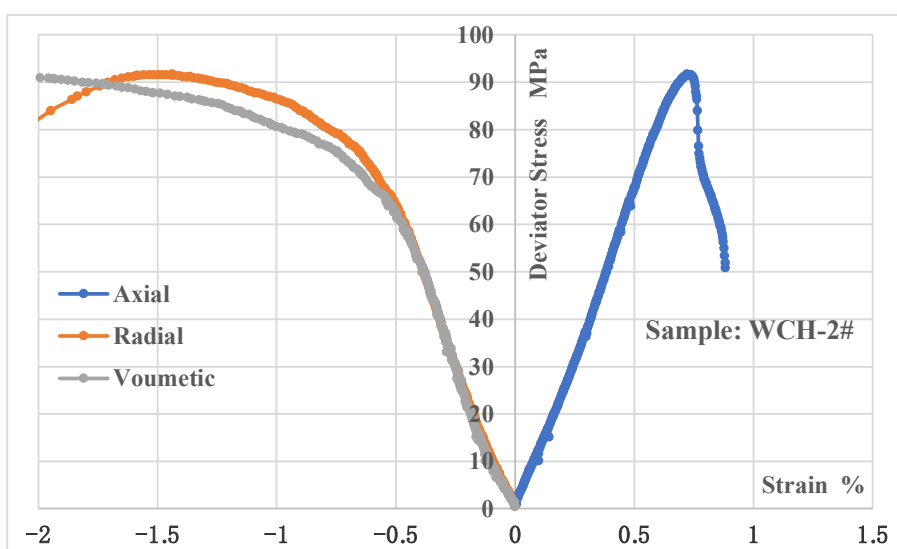

(b) Sample: WCH-2\#

Figure 1. Strains and axial deviator stress curve of triaxial experiment.

Table 1. Triaxial mechanical test results of core samples.

\begin{tabular}{lll}
\hline Sample No. & WCH -1 & WCH -2 \\
\hline Length $(\mathrm{mm})$ & 35.115 & 43.175 \\
Dia. $(\mathrm{mm})$ & 24.8 & 24.955 \\
Density $\left(\mathrm{Kg} / \mathrm{m}^{3}\right)$ & 2406 & 2571 \\
Conf. pressure $(\mathrm{MPa})$ & 40 & 40 \\
Comp. strength (MPa) & 77.5 & 91.7 \\
Elastic modulus (MPa) & 13018 & 2713 \\
PR & 0.286 & - \\
\hline
\end{tabular}

\section{In-situ Stress Field in WCH9 Block}

Usually, in-situ stress field mainly includes gravity stress, tectonic stress, formation fluid pressure and thermal stress. The vertical component of the initial in-situ stress is induced by the gravity of the overlying strata and can be calculated by density log integral. 


\subsection{Experiment Measure}

Kaiser effect test is chosen to measure formation in-situ stress by $\Phi 25 \times 50 \mathrm{~mm}$ core from the target layer. Firstly, the principal stress direction was tested by wave velocity anisotropy. The experiment curve is displayed in Figure 2.

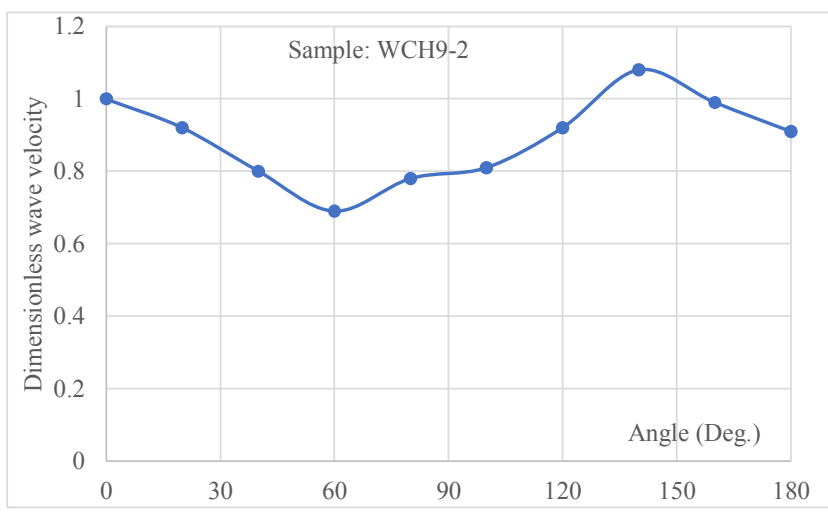

Figure 2. Test results of wave velocity anisotropy.

Then, rock sample were drilled at principal stress direction, and Kaiser effect test of the sample was completed by MTS and Locan AT acoustic emission instrument. An example test curve is shown in Figure 3. The maximum and minimum horizontal principal stresses are $78 \mathrm{MPa}$ and $63 \mathrm{MPa}$.

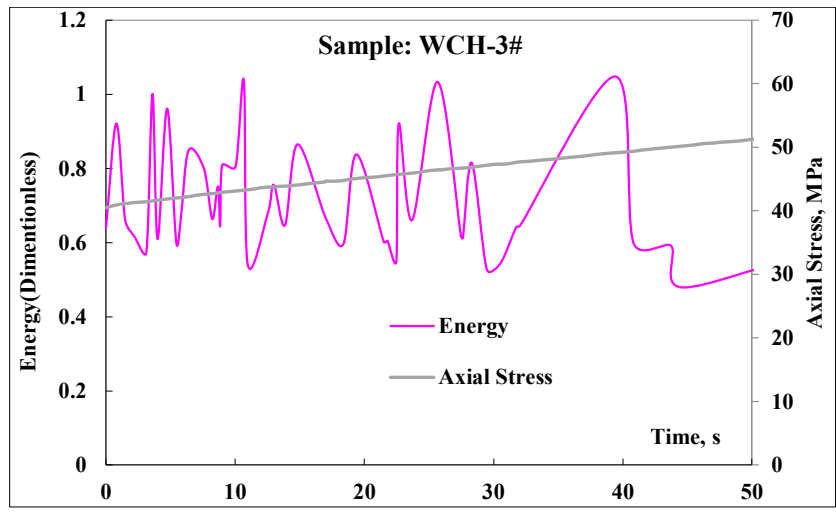

Figure 3. Test results of Kaiser effect test.

\subsection{In-Situ Stress Profile}

The in-situ stresses profiles were obtained by logging interpretation software, and the logging data comes from well WCH931. The vertical component of in-situ stress can be calculated by density logging data, the horizontal principal stress can be interpreted by Newberry model and corrected by experimental results [14]. In-situ stress distribution of WCH9 block is displayed in Figure 4.

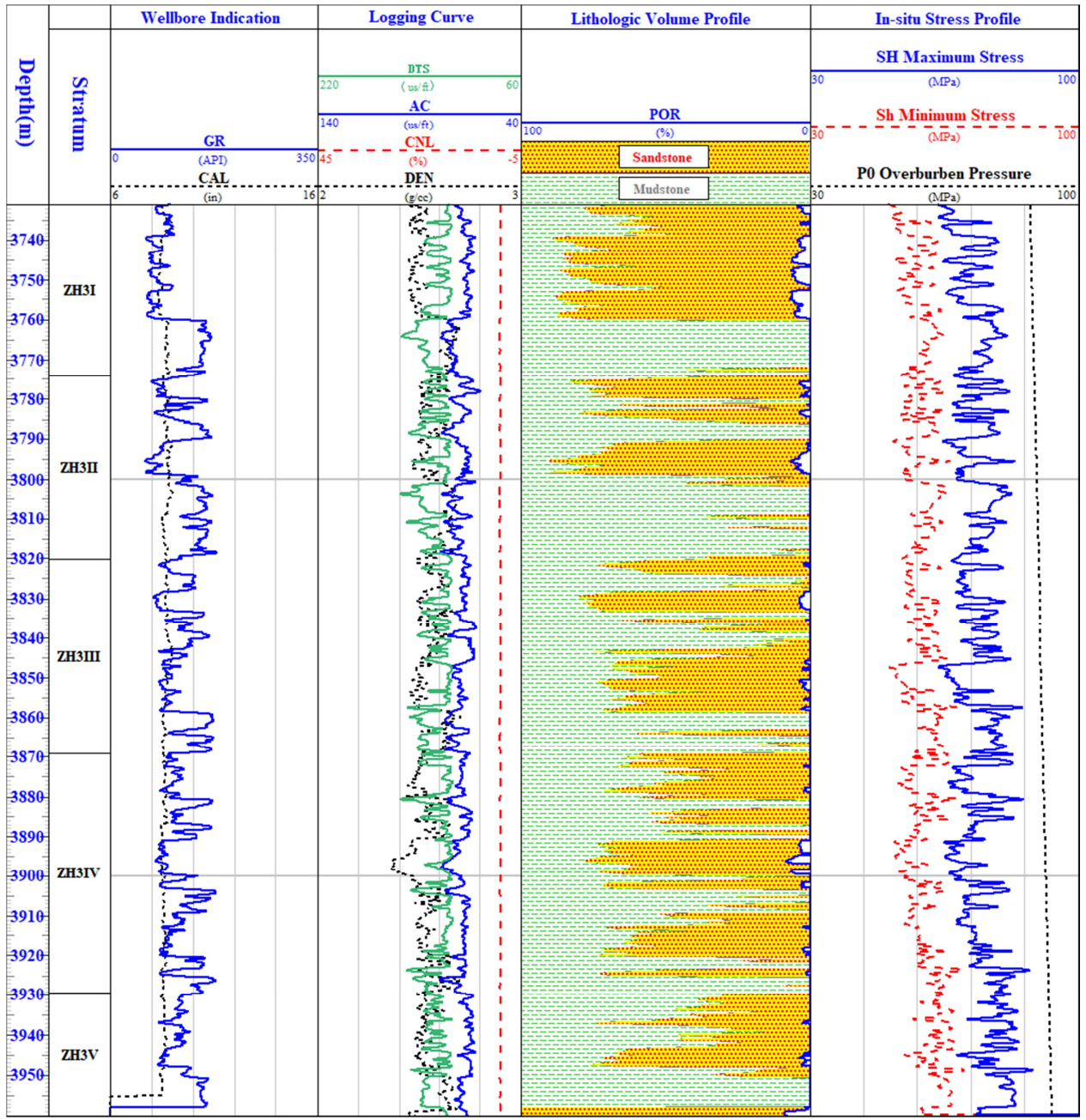

Figure 4. In-situ stress profile of the ZH formation in WCH9 block. 
The vertical stress gradient is $24.2 \mathrm{KPa} / \mathrm{m}$, the horizontal stress gradient is $16.76-21.78 \mathrm{KPa} / \mathrm{m}$ and $13.41-17.42 \mathrm{kpa} / \mathrm{m}$

\section{Prediction Model of Fracture Initiation Pressure}

Generally, formation rock is assumed as a homogeneous isotropic linear elastic medium. Three orthogonal stresses define the stress system in the underground formations, one of them can be taken along vertical direction, which is designated as $\sigma_{v}$, and the other two along horizontal directions, which are $\sigma \mathrm{H}$ and $\sigma h$. Hydraulic fracturing in deviated well is taken into account in current stress distribution from stress redistribution around the wellbore, injection fluid pressure and fracturing fluid filtration $[15,16]$, and an appropriate rock failure criterion was chosen.

\subsection{Stress Redistribution Around the Deviated Wellbore}

For any deviated well as shown in Figure 5, the well inclination angle is $\psi$ and the azimuth angle $\beta$. After the wellbore is drilled in the formation, there will be stress redistribution around the wellbore due to the stressed solid material removal and the fact that the fluid pressure in the wellbore does not match the original stresses of the formation.

Bradley generalized Kirsch formulas to the case of an arbitrarily oriented borehole with non-uniform far-field stresses [17].

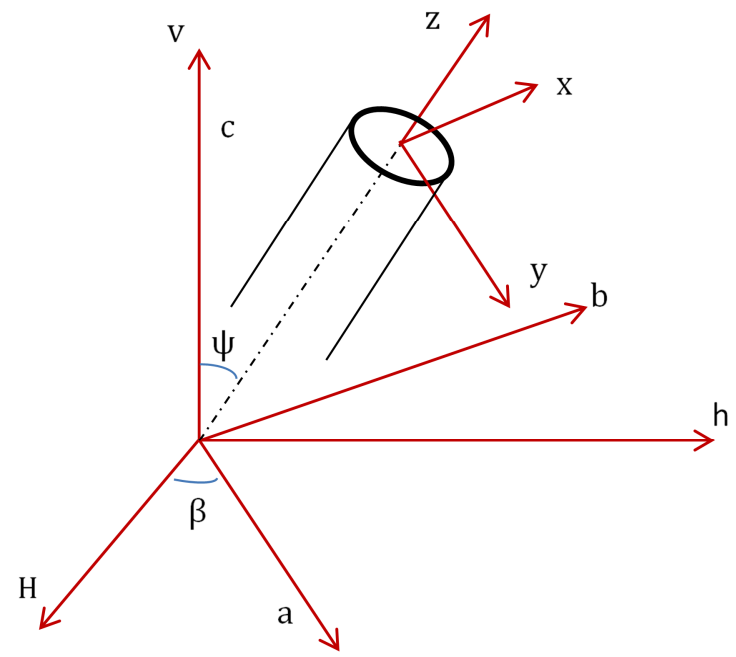

Figure 5. In-situ stress system around an inclined wellbore.

The in-situ stress distribution in coordinate system (X, Y, Z) is translated from original in-situ stress coordinate system $(\mathrm{H}$, $h, V)$.

$$
\left[\begin{array}{ccc}
\sigma_{\mathrm{x}} & \sigma_{\mathrm{xy}} & \sigma_{\mathrm{xz}} \\
\sigma_{\mathrm{zy}} & \sigma_{\mathrm{z}} & \sigma_{\mathrm{zx}} \\
\sigma_{\mathrm{yz}} & \sigma_{\mathrm{yx}} & \sigma_{\mathrm{y}}
\end{array}\right]=T\left[\begin{array}{ccc}
\sigma_{\mathrm{H}} & 0 & 0 \\
0 & \sigma_{\mathrm{h}} & 0 \\
0 & 0 & \sigma_{\mathrm{v}}
\end{array}\right] T^{T}
$$

where,

$$
\begin{aligned}
& T=\left[\begin{array}{ccc}
\cos \beta \cos \psi & \sin \beta \cos \psi & -\sin \psi \\
-\sin \beta & \cos \beta & 0 \\
\sin \psi \cos \beta & \sin \beta \sin \psi & \cos \psi
\end{array}\right] \\
& \sigma_{x y=} \sigma_{y x} \sigma_{y z=} \sigma_{z y} \sigma_{z x=} \sigma_{x z}
\end{aligned}
$$

Therefore

$$
\left\{\begin{array}{l}
\sigma_{\mathrm{x}}=\left(\sigma_{\mathrm{H}} \cos ^{2} \beta+\sigma_{\mathrm{h}} \sin ^{2} \beta\right) \cos ^{2} \psi+\sigma_{\mathrm{v}} \sin ^{2} \psi \\
\sigma_{\mathrm{y}}=\sigma_{\mathrm{H}} \sin ^{2} \beta+\sigma_{\mathrm{h}} \cos ^{2} \beta \\
\sigma_{\mathrm{z}}=\left(\sigma_{\mathrm{H}} \cos ^{2} \beta+\sigma_{\mathrm{h}} \sin ^{2} \beta\right) \sin ^{2} \psi+\sigma_{\mathrm{v}} \cos ^{2} \psi \\
\tau_{\mathrm{xy}}=0.5 \times\left(\sigma_{\mathrm{h}}-\sigma_{\mathrm{H}}\right) \sin 2 \beta \cos \psi \\
\tau_{\mathrm{zx}}=0.5 \times\left(\sigma_{\mathrm{H}} \cos ^{2} \beta+\sigma_{\mathrm{h}} \sin ^{2} \beta-\sigma_{\mathrm{v}}\right) \sin 2 \psi \\
\tau_{\mathrm{yz}}=0.5 \times\left(\sigma_{\mathrm{h}}-\sigma_{\mathrm{H}}\right) \sin 2 \beta \sin 2 \psi
\end{array}\right.
$$

In polar coordinates system, the stress components on the borehole wall were expressed as follows:

$$
\left\{\begin{array}{l}
\sigma_{r}=0 \\
\sigma_{\theta}=\left(\sigma_{x}+\sigma_{y}\right)+2\left(\sigma_{x}-\sigma_{y}\right) \cos 2 \theta-4 \tau_{\mathrm{xy}} \sin 2 \theta \\
\sigma_{z z}=\sigma_{z}-2 v\left(\sigma_{x}-\sigma_{y}\right) \cos 2 \theta-4 v \tau_{\mathrm{xy}} \sin 2 \theta \\
\tau_{r \theta}=0 \\
\tau_{\mathrm{rz}}=0 \\
\tau_{\theta z}=2\left(-\tau_{\mathrm{xz}} \sin \theta+\tau_{\mathrm{yz}} \cos \theta\right)
\end{array}\right.
$$

\subsection{Wellbore Inner Pressure and Filtration Stress by Injection Fracturing Fluid}

The high rate fluid injection of hydraulic fracturing is regarded as a static process, and the expression of radial and circum-axial stress components under column coordinates $(\mathrm{r}, \theta, \mathrm{z})$ is calculated by elastic mechanics theory as follows [17]

$$
\left\{\begin{array}{l}
\sigma_{r}=p_{i n} \\
\sigma_{\theta}=-p_{i n} \\
\sigma_{z z}=c p_{i n}
\end{array}\right.
$$

According to Lubinski's results [18], the additional stress generated by fracturing fluid filtration in porous elastic media near the well was established.

$$
\left\{\begin{array}{l}
\sigma_{r}=-\delta \varphi p_{i n} \\
\sigma_{\theta}=\delta(A-\varphi)\left(p_{i n}-p_{p}\right) \\
\sigma_{z z}=\delta(A / 2-\varphi)\left(p_{\text {in }}-p_{p}\right)
\end{array}\right.
$$

where,

$$
A=\frac{\alpha(1-2 v)}{1-v}
$$

\subsection{Total Stress Distribution Around Borehole Wall}

Considering the current in-situ stress to inject fluid into the well and fracturing fluid filtration, the mathematical model of 
stress field at arbitrarily oriented wellbore borehole wall is presented based on the principle of stress superposition as follows:

$$
\left\{\begin{array}{l}
\sigma_{r}=p_{i n}-\delta \phi p_{i n} \\
\sigma_{\theta}=-p_{i n}+\sigma_{x}+\sigma_{y}+2\left(\sigma_{x}-\sigma_{y}\right) \cos 2 \theta \\
-4 \tau_{\mathrm{xy}} \sin 2 \theta-\delta[A-\phi]\left(p_{i n}-p_{p}\right) \\
\sigma_{z z}=c p_{i n}+\sigma_{z}-2 v\left(\sigma_{x}-\sigma_{y}\right) \cos 2 \theta \\
-4 v \tau_{\mathrm{xy}} \sin 2 \theta+\delta\left[\frac{A}{2}-\phi\right]\left(p_{\mathrm{in}}-p_{p}\right) \\
\tau_{r \theta}=0 \\
\tau_{\mathrm{rz}}=0 \\
\tau_{\theta z}=2\left(-\tau_{\mathrm{xz}} \sin \theta+\tau_{\mathrm{yz}} \cos \theta\right)
\end{array}\right.
$$

\subsection{Fracture Initiation Pressure Prediction Model}

Early studies have proven that maximum tensile stress criterion is the most accurate and widely used to predict FIP. Based on the composite stress theory, the three-dimensional stress field transformation on the borehole wall with arbitrary well inclination and azimuth angle is the main stress.

$$
\left\{\begin{array}{l}
\sigma_{1}=\sigma_{\mathrm{r}} \\
\sigma_{2}=\frac{1}{2}\left[\left(\sigma_{\theta}+\sigma_{\mathrm{zz}}\right)+\sqrt{\left(\sigma_{\theta}-\sigma_{\mathrm{zz}}\right)^{2}+4 \tau_{\theta \mathrm{z}}^{2}}\right] \\
\sigma_{3}=\frac{1}{2}\left[\left(\sigma_{\theta}+\sigma_{\mathrm{zz}}\right)-\sqrt{\left(\sigma_{\theta}-\sigma_{\mathrm{zz}}\right)^{2}+4 \tau_{\theta \mathrm{z}}^{2}}\right]
\end{array}\right.
$$

According to principle of effective stress and the first strength theory, the fracture initial pressure criterion is expressed as follows:

$$
\sigma_{3}-\eta p_{i n} \leq-\sigma_{t}
$$

\section{Fracture Initiation Pressure of Inclined Well in WCH9 Block}

The payzone is mainly concentrated in $\mathrm{ZH}$ formation, with a vertical depth of nearly $4000 \mathrm{~m}$. The porosity is $15 \%$. YM is $12.8 \mathrm{GPa}$ and $\mathrm{PR}$ is 0.286 . The vertical stress is $94 \mathrm{MPa}$, the horizontal principal stress is $78 \mathrm{MPa}$ and $63 \mathrm{MPa}$, and FIP change curves with the well trajectory is shown in Figure 6.

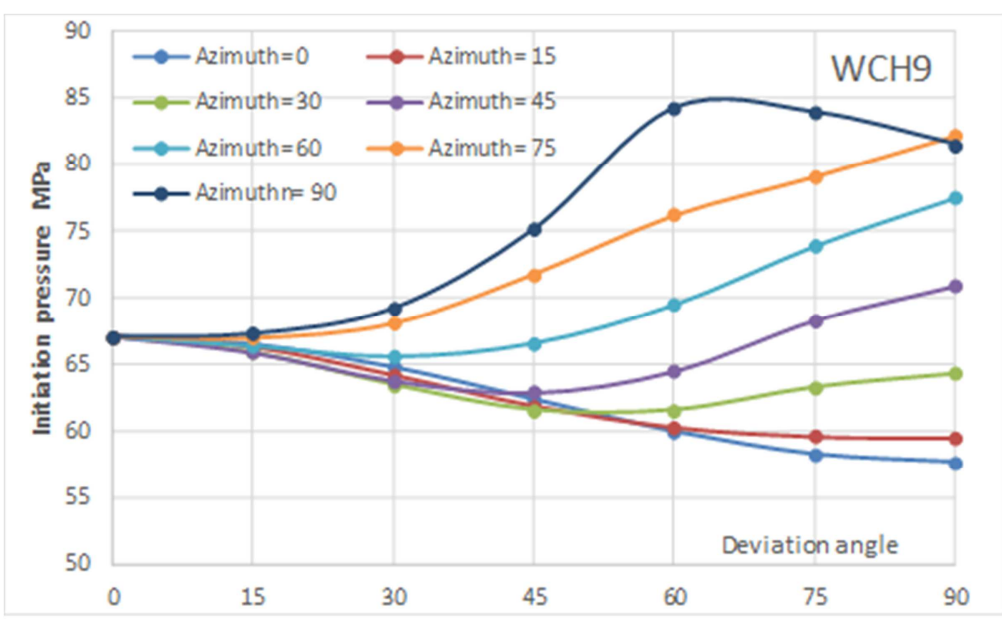

(a)

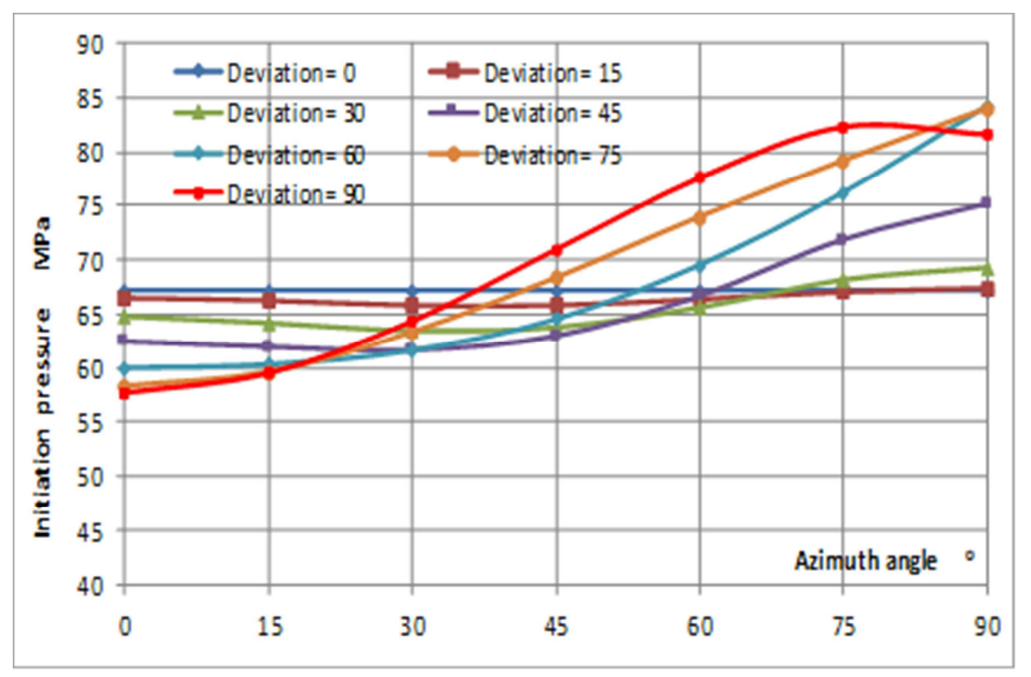

(b)

Figure 6. Fracture initiation pressure for wellbore deviation and azimuth angle. 
FIP of vertical wells in the gas field is $67 \mathrm{MPa}$. FIP in deviated well generally increases with wellbore azimuth angle, and its variation with well inclination is more complicated and related to azimuth.

FIP increase with the growth of inclination when azimuth angle is greater $30^{\circ}$. It goes down if azimuth angle is less $30^{\circ}$.

The maximum FIP mainly appears when the well inclination angle is greater than $60^{\circ}$ and the azimuth angle is $60^{\circ}$.

The azimuth angle is about $40^{\circ}-70^{\circ}$ from statistics information in horizontal well in WCH9 gas field. Therefore, the FIP can reach $71 \mathrm{MPa}$ and $81.5 \mathrm{MPa}$ and is much higher than $67 \mathrm{MPa}$ in vertical well.

\section{Conclusion}

Based on the study results of experiment and numerical simulation in payzone in $\mathrm{WCH} 9$, the conclusions are obtained as following:

(1) The static Young's elastic modulus and Poisson's ratio of the reservoir are $12-13 \mathrm{GPa}$ and 0.286 .

(2) In the payzone of WCH9 block, the vertical stress is $94 \mathrm{MPa}$, and the maximum and minimum horizontal stresses are $78 \mathrm{MP}$ and $63 \mathrm{MPa}$.

(3) FIP in vertical wells is $67 \mathrm{MPa}$. The FIP generally goes up with the increase of inclination angle. And its variation with well inclination is more complicated and related to azimuth. FIP increases with growth of inclination angle when azimuth angle is greater than $30^{\circ}$, it goes down if azimuth angle is less than $30^{\circ}$.

(4) The maximum FIP mainly appears when the well inclination angle is greater than $60^{\circ}$ and the azimuth angle is $60^{\circ}$. The azimuth angle is about $40^{\circ}-70^{\circ}$ of horizontal well in WCH9 block, and FIP can reach $71 \mathrm{MPa}$ and $81.5 \mathrm{MPa}$ and is much higher than $67 \mathrm{MPa}$ in vertical well.

\section{Nomenclature}

c- Operation impact factor, Decimal;

$\mathrm{p}_{\text {in }}$-Hydraulic fracturing or fracture initiation pressure is injected into the wellbore, $\mathrm{MPa}$;

$\mathrm{p}_{\mathrm{p}}$-Formation fluid pressure, $\mathrm{MPa}$;

$\alpha$-Biot factor, Dimensionless;

$\beta$ - Azimuth angle of inclined wellbore, degree;

$\delta$-Permeability coefficient, Dimensionless;

$\varphi$-Formation porosity, Decimal;

$v$-Poisson's ratio, Decimal;

$\psi$-Deviation angle of inclined wellbore, degree;

$\theta$-Angular position around wellbore circumference, degree.

$\eta$-Pore pressure contribution coefficient, Decimal;

$\sigma_{\mathrm{t}}$ - Rock tensile strength, $\mathrm{MPa}$;

$\sigma_{\mathrm{H}}, \sigma_{\mathrm{h}}, \sigma_{\mathrm{v}}$-Maximum horizontal principal stress and the minimum principal stress in situ and the vertical principal stress, $\mathrm{MPa}$;

$\sigma_{\mathrm{x}}, \sigma_{\mathrm{y}}, \sigma_{\mathrm{z}}$ - Normal stresses of three directions in the XYZ coordinate system, $\mathrm{MPa}$;

$\sigma_{\mathrm{r}}, \sigma_{\theta}, \sigma_{\mathrm{zz}}$-Wellbore radial, tangential and axial stresses, respectively, $\mathrm{MPa}$;

$\sigma_{1}, \quad \sigma_{2}, \quad \sigma_{3}-$ Maximum, intermediate and minimum principal stresses, $\mathrm{MPa}$;

$\tau_{\mathrm{xy}}, \tau_{\mathrm{yz}}, \tau_{\mathrm{zx}}$ - The shear stresses in the coordinate system $\mathrm{XYZ}, \mathrm{MPa}$;

$\tau_{\mathrm{r} \theta}, \tau_{\mathrm{rz}}, \tau_{\theta \mathrm{z}}-$ Cylindrical wellbore shear stresses in the coordinate system $(\mathrm{r}, \theta, \mathrm{z}), \mathrm{MPa}$.

\section{Acknowledgements}

This research was supported by project "Research on fracturing technology of low permeability gas reservoir in the western South China Sea (CCL2019ZJFN11897)", the authors wish to thank the CNOOC (China) Co., Ltd. for permission to publish the paper.

\section{References}

[1] Hubbert M K, Willis D G: Mechanics of hydraulic fracturing $[\mathrm{J}]$, Metallurgical and Petroleum Engineering, 1957, 210 (6): $153-163$.

[2] Yew C H, Li Y: Fracturing of a deviated wells [C]. SPE16930, 1987.

[3] Wan Renpu: Oil production technology manual (Ninth Volume) [M]. Beijing, Petroleum Industry Press, 1998.

[4] Daneshy A A: A study of inclined hydraulic fractures [J]. SPEJ, April, 1973.

[5] Yu Xiongying, Xing Jiguo, Wang Xianying: Fracture pressure and fracture orientation of inclined well [J]. Journal of Jianghan Petroleum Institute, 1994 (1): 57-61.

[6] Zhou Daiyu, Guo Jianchun, Zhao Jinzhou, et al. Study on fracture initiation of extended reach wells in open hole [J]. Journal of Southwest Petroleum University (Natural Science Edition), 2002, 24 (6): 32-35.

[7] Chen Mian, Chen Zhixi, Huang Rongzun: Research on initiation of hydraulic fractures in highly deviated wells [J]. Journal of the University of Petroleum, China, 1995 (2): 30-35.

[8] Hossain M M, Rahman M K, Rahman S S: A comprehensive monograph for hydraulic fracture initiation from deviated well bores under arbitrary stress regimes [C]. SPE 54360, 2002.

[9] Weng X. Fracture initiation and propagation from deviated wellbores. In SPE annual technical conference and exhibition, Houston, Texas, 3-6 October 1993.

[10] Xian Shi, Yuanfang Cheng, Zheng Yuan: The Prediction of Fracture Pressure for the Deviated Wells and the Analysis of Relating Parameters [J]. Science Technology and Engineering. 2012, 12 (31), 8205-8209.

[11] Fanhui Zeng, Botao Tang, Tao Wang: Prediction model of fracture initiation pressure of open hole well considering penetration effect [J]. Natural Gas Geoscience. 2019, 30 (4): $550-555$. 
[12] Juhui Zhu, Ruohan $\mathrm{Hu}$, Zhoumei Gen, et al. A prediction of breakdown pressure from damaged deviated well [C], IOP Conference Series: Earth and Environmental Science, 2021.

[13] Roostaei, M, Sharbatian, A, Fattahpour, V. An Analytical Model for Hydraulic Fracture Initiation in Deviated Wellbores. prepared for presentation at the 53rd US Rock Mechanics/Geomechanics Symposium held in New York, NY, USA, 23-26 June 2019.

[14] Liu Xiangjun, Liu Tangyan and Liu Shiqiong. Logging Principle and Engineering Application: Rich Media [M]. Beijing: Petroleum Industry Press, 2018.
[15] $\mathrm{Hu}$ Yongquan. Theory and design methods of hydraulic fracturing (CNPC training material). Nanchong, 1999.

[16] Fjar E, Holt R M, Raaen A M, Risnes R. Petroleum related rock mechanics. $2^{\text {nd }}$ ed. Amsterdam: Elsevier. 2008.

[17] Bradley W B. Failure of inclined boreholes [J]. Journal of Energy Resources Technology, 1979, 101 (4), 232- 239.

[18] Lubinski A: The theory of elasticity for porous bodies displaying a strong pore structure [C]. Proc. 2nd U. S. National Congress of Applied Mechanics. 1954. 